\section{Links Between Life Stories and Identity Profiles in Emerging Adults From Georgia}

\author{
Nino Skhirtladze', Nino Javakhishvili', Seth J. Schwartz ${ }^{2}$, \\ and Koen Luyckx ${ }^{3}$
}

Emerging Adulthood

$1-12$

(C) 2017 Society for the

Study of Emerging Adulthood

and SAGE Publishing

Reprints and permission:

sagepub.com/journalsPermissions.nav DOI: $10.1177 / 2167696817746039$

journals.sagepub.com/home/eax

(S)AGE

\begin{abstract}
In this study, we examine personal identity formation using two approaches: a dual-cycle model of identity development and a narrative life-story model. We used quantitative and qualitative methods for studying personal identity: Luyckx et al.'s Dimensions of Identity Development Scale and D. P. McAdams' life-story interview. Using six cases selected from a sample of 62 Georgian emerging adults, we illustrate how identity profiles created using six identity dimensions (exploration in breadth, commitmentmaking, identification with commitment, reflective exploration in depth, reconsideration of commitment, and ruminative exploration) are reflected in life stories depicting participants' paths toward identity commitments and their ideas about the future and life themes. This article demonstrates how identity dimensions are connected to the context and how this connection is manifested in their life stories. The research illustrates theoretical exemplification by case studies and exemplifies the manifestation of dual-cycle identity development theorizing in case examples through narratives.
\end{abstract}

\title{
Keywords
}

identity profiles, identity narratives, Georgian Republic, identity development

A number of authors have pointed to the need to apply different theoretical and methodological approaches simultaneously to the study of identity (McLean \& Pasupathi, 2012; J. S. Schwartz, Luyckx, \& Crocetti, 2015; Syed, 2010). This article describes personal identity development from two different approaches: the narrative identity model (D. McAdams, 2001, 2011) and the dual-cycle model of identity development (Luyckx et al., 2008; Luyckx, Schwartz, Goossens, Beyers, \& Missotten, 2011). From a developmental perspective, the study of personal identity has its roots in Erikson's seminal work, where he cast identity as the fundamental task of adolescence and the transition to adulthood. In its broadest sense, identity development can be described as the process through which a person answers the questions "who am I?" and "how do I fit into the world around me?" The answers to these questions might depend on the specific theoretical conceptualization under consideration (Vignoles, Schwartz, \& Luyckx, 2011)and as a result, it may be useful to consider multiple theoretical approaches simultaneously.

The importance of decision-making and life choices in identity development is outlined within identity status approaches (Crocetti, Rubini, \& Meeus, 2008; Luyckx et al., 2008, 2011; Marcia, 1966), whereas autobiographical reasoning and the capacity to construct a life story are central within the narrative approach to identity (D. McAdams, 2001, 2011). In the present work, using six case studies, we illustrate how these two metatheoretical approaches and methods complement each other and provide a richer picture of the identity formation process than would be produced using either approach alone. Specifically, using a quantitative, status-based approach, we measure identity dimensions and create typological groups based on these dimensions. Using the qualitative life-story method, we illustrate the content that these dimensions and profiles may represent and how these dimensions are contextualized within life stories (see McLean, Syed, Yoder, \& Greenhoot, 2014). In the following sections, we review these identity status and narrative approaches in more detail.

\section{Identity Status Approaches}

Within Marcia's (1966) identity status approach, individuals are viewed as active, motivated agents who direct their own

\footnotetext{
'Illia State University, Tbilisi, Georgia

${ }^{2}$ Miller School of Medicine, University of Miami, Miami, FL, USA

${ }^{3} \mathrm{KU}$ Leuven, Leuven, Belgium

Corresponding Author:

Nino Skhirtladze, PhD, Ilia State University, Tbilisi 0162, Georgia.

Email: nino.skhirtladze.2@iliauni.edu.ge
} 
self-development (see Kroger \& Marcia, 2011, for a review; D. McAdams \& Zapata-Gietl, 2015). Marcia proposed the task of identity development as consisting of two primary processes: exploration, which refers to examining alternatives in identity-relevant life domains (e.g., profession, values and beliefs, relationships), and commitment, which refers to adhering to one of more such identity alternatives. Marcia divides each of these processes into "presence" versus "absence" and defines four identity statuses: achievement, where the person has gone through a process of exploration and has enacted commitments; foreclosure, where commitments have been enacted without much prior exploration; moratorium, where the person is in the process of exploration but has not enacted commitments; and diffusion, where the person is not exploring and has not enacted commitments. Marcia's model has been the most widely utilized neo-Eriksonian theoretical approach, inspiring many theoretical and empirical publications (Kroger \& Marcia, 2011). Marcia's approach has also inspired the development of expanded identity models (e.g., Crocetti et al., 2008; Luyckx et al., 2008) that propose additional processes and statuses. Here we focus on Luyckx et al.'s (2008) dual-cycle model of identity.

In their initial extension of Marcia's paradigm, Luyckx et al.'s dual-cycle model describes two cycles of identity formation: commitment formation and commitment evaluation. The initial version of this model examined four dimensions of identity development, with exploration in breadth and commitmentmaking (commitment formation) corresponding to Marcia's initial dimensions. Luyckx et al. also proposed two additional dimensions: exploration in depth, where one further evaluates commitments that have already been enacted, and identification with commitment (commitment evaluation), where the person internalizes and develops increasing certainty regarding existing commitments (Luyckx, Goossens, Soenens, \& Beyers, 2006). A fifth dimension, ruminative exploration, was added to the model later and refers to obsessing over the task of making choices, so much so that one becomes paralyzed with indecision (Luyckx et al., 2008; Luyckx, Soenens, Goossens, Beckx, \& Wouters, 2008). Ruminative exploration is a maladaptive identity dimension, in that it interferes with productive exploration, with the enactment of commitments, and with self-esteem and other forms of well-being (Luyckx et al., 2013). In some later empirical studies (Beyers \& Luyckx, 2016; Skhirtladze, Javakhishvili, Schwartz, Beyers, \& Luyckx, 2016; Zimmermann, LannegrandWillems, Safont-Mottay, \& Cannard, 2013), exploration in depth has been empirically separated into two distinct dimensions: (a) reflective exploration in depth and (b) reconsideration of commitment (Crocetti et al., 2008). Reflective exploration in depth involves reflecting on one's existing commitments, whereas reconsideration of commitment denotes critically appraising one's commitments and being ready to change them if they are deemed unsatisfactory.

Using cluster-analytic methods, the dual-cycle model has been used to derive identity profiles. These cluster solutions have generally included Marcia's original foreclosed, moratorium, and achieved statuses, two varieties of diffusion, and an undifferentiated status (Luyckx et al., 2008; S. J. Schwartz et al., 2011). Individuals classified as achieved score high on commitment-making, identification with commitment, exploration in breadth, and exploration in depth but low in ruminative exploration. Foreclosed individuals score high on both commitment and low on all three exploration dimensions. Individuals in the searching moratorium status score high on all three exploration dimensions and low on both commitment dimensions. The two varieties of diffusion have been labeled as troubled diffusion (previously diffused diffusion) and carefree diffusion. Troubled diffusion refers to individuals who are unable to initiate or sustain exploration in breadth long enough to establish commitments, whereas carefree diffusion characterizes individuals who are uninterested in identity issues altogether. An undifferentiated profile scores close to the sample mean on all of the component dimensions.

Identity dimensions and profiles have been studied in connection with positive and negative psychological functioning. Commitment-making, identification with commitment, and exploration in breadth have been found to be associated with higher levels of psychological adjustment, whereas ruminative exploration and reconsideration of commitment were found to be associated with more negative outcomes (Beyers \& Luyckx, 2016; Luyckx et al., 2013; Ritchie et al., 2013). In terms of profiles, achievement and foreclosure profiles have been found to be associated with the highest levels of positive functioning, with foreclosed individuals somewhat lower in anxiety and in goal-directedness compared to achieved individuals. Searching moratorium and undifferentiated profiles have been associated with moderate levels of adjustment. Carefree and troubled diffusion have been associated with the lowest positive adjustment, with some differences emerging between these two diffused statuses (e.g., higher risk-behavior and lower anxiety in carefree diffusion than in troubled diffusion; Luyckx et al., 2008; S. J. Schwartz et al., 2011). The dual-cycle model of identity development has been studied in many countries and has been shown to operate equivalently across different cultural contexts, although some cultural specificities were identified as well (Crocetti, Luyckx, Scrignaro, \& Sica, 2011; Luyckx et al., 2008; Mannerström, Hautamäki, \& Leikas, 2016; Mastrotheodoros \& Motti-Stefanidi, 2016; Pesigan, Luyckx, \& Alampay, 2014; S. J. Schwartz et al., 2011; Skhirtladze et al., 2016; Zimmermann et al., 2013).

\section{Narrative Identity Model}

D. P. McAdams's (2001) narrative identity model is concerned primarily with people's life stories, the ways in which the stories are told and interpreted, and the extent of experienced self-authorship (e.g., deriving meaning from major events; D. McAdams \& McLean, 2013). Narrative methods focus on one's subjective understanding of how one's life has unfolded including the presence or absence of a sense of temporal continuity even as circumstances and the person himself or herself continue to change and evolve (D. McAdams \& Zapata-Gietl, 2015). According to Habermas and Bluck (2000), beginning in adolescence, one becomes capable of constructing a life 
story - and not coincidentally, adolescence is the time when Erikson (1968) believed that individuals acquired the perspective-taking abilities necessary to support exploration and self-reflection. Narrative identity remains an ongoing project from adolescence onward. Although they are stable to some extent, life narratives are also updated by adding new episodes and transforming old ones (Cox \& McAdams, 2010; D. P. McAdams et al., 2006). An individual narrative is based on life events and circumstances, but these facts are chosen and organized by the individual. The individual uses imagination and integration to transform facts into stories but does not have absolute freedom and is constrained by existing realities (e.g., physical, biological, cultural, and historical).

In empirical studies, narrative identity is examined through life-story interviews consisting of different sections referring to various episodes of one's past and future life. Substantial empirical research has been conducted on various dimensions and features of narratives. For example, motivational themes of agency and communion reflect the degree to which one views oneself as the initiator and in control of one's life course and occurring changes (agency) or tries to achieve harmony and togetherness with the environment (communion). Affective themes of contamination and redemption refer to sequences of life events from positive to negative (contamination) or from negative to positive (redemption). The structural coherence of life stories refers to the degree of integration within one's life story, and structural complexity describes the degree to which one uses multiple viewpoints and perspectives in narration (Adler et al., 2017). Further, different features of narratives within life-story interviews have been found to be linked to certain developmental outcomes. For example, high elaboration and self-exploration have been found to be associated with high ego development, whereas redemptive life stories have been associated with higher life satisfaction and emotional well-being (D. P. McAdams, 2008; D. McAdams \& McLean, 2013). Within the narrative approach, the key process is autobiographical reasoning, which is defined as active reflection on one's past in order to connect it to one's present. Formulated differently, autobiographical reasoning is a process through which the individual reaches overall conclusions about the self based on episodes from her or his life. Autobiographical reasoning provides unity and meaning to life narratives (D. McAdams, 2001, 2011).

\section{Republic of Georgia as a Context for Identity Research}

Traditionally, the majority of identity research has been conducted in North America and Western Europe, regions where the needs and desires of the individual person are prioritized over those of the family or other social group (Gelfand et al., 2011). The individualistic and decontextualized character of the identity status model is not surprising, given that it was developed in North America-and although they do attend more to context, narrative models may still be somewhat individualistic because they frame the individual person as the center of the story. More work is needed on developmentally based identity models in more strongly collectivistic regions of the world (S. J. Schwartz, Zamboanga, Meca, \& Ritchie, 2012). Such a recommendation builds on the need for more emerging adulthood research, and more psychological research generally, outside of North America and Western Europe (Arnett, 2008; S. J. Schwartz, 2016).

The present study was conducted in Georgia, a post-Soviet country where familial, community, and national contexts for identity development are undergoing rapid and wholesale change (Roberts \& Pollock, 2009). This context, and others like it, is understudied in identity research. Many features of the Georgian context make it different from those where identity research has been most commonly conducted. Georgia as a former communist country that experienced a dramatic socioeconomic collapse during Soviet occupation and has, since the fall of the Soviet Union in 1991, been in a process of perpetual transition in terms of political, economic, social, and cultural life (Roberts, Pollock, Manasyan, \& Tholen, 2008).

Georgian culture is high on collectivism, cultural embeddedness, and respect for social ties and guidelines (House, Hanges, Javidan, Dorfman, \& Gupta, 2004; S. H. Schwartz, 2006). These conditions likely influence young people's identity development differently compared to the more individualistic North American and Western European contexts where most identity research is conducted. Indeed, contrary to results from Western contexts, in Georgia exploration in breadth was highly correlated with ruminative exploration (Skhirtladze et al., 2016). These results were interpreted as suggesting that exploration in breadth is dissatisfying and frustrating, perhaps because of limited economic resources and opportunities in Georgia. Further, Skhirtladze, Javakhishvili, Schwartz, and Luyckx (2017) found that tendencies (a) to avoid proactive identity work and (b) to follow social conventions and norms when approaching life choices were closely related. Such a finding may be explained by specifics of the Georgian culture in terms of high reliance on social norms.

\section{The Present Study: Combining Dual-Cycle and Narrative Models}

Over the last decade, many theoretical treatises and empirical studies have attempted to address the growing need to integrate disparate approaches to the study of identity (Carlsson, Wängqvist, \& Frisén, 2016; McLean \& Pasupathi, 2012; McLean \& Pratt, 2006; McLean, Syed, \& Shucard, 2016). However, several aspects of integration require further attention from researchers. For example, whereas status-model questionnaires primarily index identity formation at present, narratives focus on past events that have led up to the present moment (McLean \& Pasupathi, 2012). Furthermore, identity processes unfold in context - in a specific place and time that influences and directs these processes (Baumeister \& Muraven, 1996). However, process-oriented models often do not attend to context. Narratives can help to integrate context with processes by providing more information on the settings in which identityrelated events occur. 
In the present article, we present life stories from six emerging adults, each of whom was classified into a different identity status using the Dimensions of Identity Development Scale (DIDS), a status-based quantitative questionnaire. We utilize these six examples as case studies (Carlsson et al., 2016). Our aim here is not to test a specific set of hypotheses but rather to exemplify theory and augment existing quantitative knowledge by illustrating how identity processes unfold within the life stories of six individuals with different identity profiles. The aim of theory exemplification using case studies is to show how concepts of theory manifest themselves in individual cases, thus presenting "individuality, imperfection, and idiosyncrasy of real lives" (Robinson \& McAdams, 2015, p. 4). In the present article, we aim to illustrate how identity profiles, created using cluster-analytic methods with the six identity dimensions from the dual-cycle model, are reflected in life stories. We will describe routes toward identity commitment (or lack of it), ideas about the future, and life themes across different identity profiles. We also aim to demonstrate how identity is connected to context (familial, cultural, and socioeconomic) and how these connections are manifested in different life stories.

\section{Method}

\section{Sampling and Participants}

The six case studies were drawn from a larger study of 62 Georgian emerging adults aged from 19 to 26 (Mean age 22.37, SD $=1.7 ; 30$ male and 32 female). Eighty percent of participants in the larger study lived with their parents, and only two were married. All participants were university students. Half of the sample was planning to go abroad for study purposes. The sample was recruited from the databases maintained by two state universities in Georgia with the help of university administrators. Institutional review board approval and participants' informed consent were obtained before starting the investigation. The study took 1.5 to $2.5 \mathrm{hr}$ to complete. At the beginning of the interview, participants were asked about their demographic characteristics (age, education, and marital status). All 62 study participants completed the questionnaire that measures six identity dimensions (DIDS), followed by the lifestory interview. At the end, participants received a small gift as compensation for their participation.

Consistent with prior work, we conducted cluster analyses to determine membership in each of the six identity profiles. Previous studies have used such a two-step clustering procedure to create identity clusters. First, hierarchical clustering using Ward's method with squared Euclidean distances was conducted. Second, a k-means clustering procedure, using cluster centers from the first step as starting values, was used to optimize the cluster solution (Luyckx et al., 2008; S. J. Schwartz et al., 2011). However, because our current sample size was too small to provide data on cluster centers through hierarchical clustering, we used the final cluster centers from a previous study with a larger sample of Georgian emerging adults (Skhirtladze et al., 2016) as starting values for the second

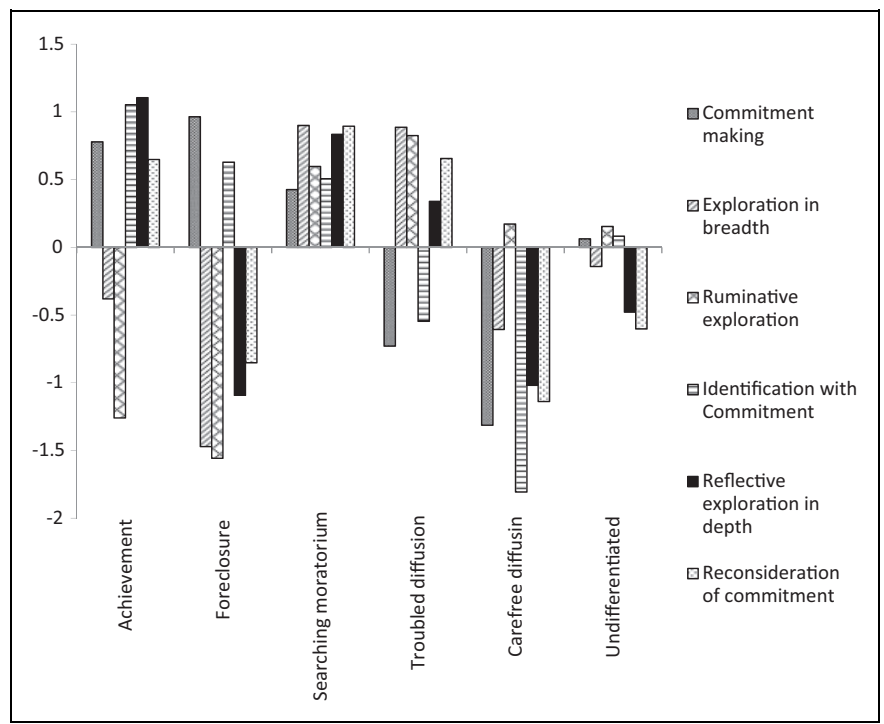

Figure I. Six identity profiles as a combination of identity dimensions.

step (i.e., a noniterative, k-means clustering procedure). The solution that we obtained in the present sample was extremely similar to the larger prior sample one and matched the clusters obtained in prior studies in Western countries (Luyckx et al., 2008; S. J. Schwartz et al., 2011). As case studies, we used cases with the greatest degree of correspondence with the clusters obtained by Skhirtladze, Javakhishvili, Schwartz, Beyers, and Luyckx (2016). These six cases are presented in Figure 1.

Specifically, to provide theoretical exemplification, we used a typical case strategy by choosing one case from each of the six identity profiles based on quantitative correspondence to the profiles (Robinson, 2014). Quantitative correspondence was defined in terms of how much the scores deviated from the mean on each component dimension. Table 1 presents information on each participant's age, gender, and DIDS scores, as well as means and standard deviations ( $S D \mathrm{~s}$ ) from the larger sample (displayed below the dimension labels in the first row). The overall sample mean and $S D$ s are provided to place each case's scores into context. For example, the 4.60 score on commitment-making provided by the achieved and foreclosed participants is $.88 S D$ above the overall sample mean for commitment-making. The remainder of this article focuses primarily on these six participants.

\section{Measures}

Status measure: DIDS. The DIDS focuses on six identity dimensions in the domain of future goals: commitment-making ("decided on the direction I want to follow in life"), identification with commitment ("plans for the future offer me a sense of security"), exploration in breadth ("regularly try to figure out which lifestyle would suit me"), reflective exploration in depth ("think about the future plans I already made"), reconsideration of commitment ("work out for myself if the goals I put forward in life really suit me"), and ruminative exploration ("doubtful about what I really want to achieve in life"). A 5-point response 
Table I. Participants' Age, Gender, DIDS Scores, Mean Scores, and Standard Deviations From the Larger Sample (Below the Dimension Names in the First Row).

\begin{tabular}{|c|c|c|c|c|c|c|c|c|}
\hline \multirow[b]{2}{*}{ Identity Profile } & \multirow[b]{2}{*}{ Age } & \multirow[b]{2}{*}{ Gender } & \multicolumn{6}{|c|}{ Mean Scores of Six Identity Dimensions } \\
\hline & & & $\begin{array}{c}\mathrm{CM} \\
3.97(.72)\end{array}$ & $\begin{array}{c}\text { EB } \\
3.73(.83)\end{array}$ & $\begin{array}{c}\operatorname{IwC} \\
3.96(.66)\end{array}$ & $\begin{array}{c}\text { RED } \\
3.56(.97)\end{array}$ & $\begin{array}{c}\text { REC } \\
3.38(.83)\end{array}$ & $\begin{array}{c}\text { RE } \\
3.08(.88)\end{array}$ \\
\hline Achievement & 23 & Male & 4.60 & 4.00 & 5.00 & 4.50 & 2.74 & 2.00 \\
\hline Foreclosure & 22 & Female & 4.60 & 3.20 & 4.80 & 5.00 & 3.67 & 2.00 \\
\hline Moratorium & 23 & Female & 4.20 & 4.40 & 4.20 & 4.00 & 4.00 & 4.00 \\
\hline Undifferentiated & 22 & Female & 3.60 & 4.00 & 4.00 & 3.50 & 3.00 & 3.20 \\
\hline
\end{tabular}

Note. The first row presents mean scores of the following identity processes: $\mathrm{CM}=$ commitment-making; $\mathrm{EB}=$ exploration in breadth; IwC = identification with commitment; RED = reflexive exploration in depth; REC = reconsideration of commitment; RE = ruminative exploration. DIDS $=$ Dimensions of Identity Development Scale.

scale is used, ranging from 1 (totally disagree) to 5 (totally agree). Cronbach's $\alpha$ s for the DIDS subscales varied from .56 to .89 .

Narrative measure: Life-story interview. The life-story interview contains eight sections - life chapters, key scenes, future script, life challenges, personal ideology, life theme, and reflection. Although participants were asked to respond to all the sections from the D. P. McAdams' (2008) life-story interview, only four were used in the present analyses: life chapters, turning point experience from key scenes, future script, and life theme. In the life chapters section, participants were asked to imagine their life as though it were a book or novel, list what the main chapters in the book might be, and describe each of the chapters. For turning point experiences, participants were asked about episodes that marked an important change in their life story, their thoughts and feelings about these episodes, and the meaning of each event within the larger life story. In the future section, participants described what they saw as the next chapter in their lives. Finally, in the life theme section, participants were asked to discern a central theme, message, or idea that ran throughout the story with all its chapters, scenes, and challenges, and extending back into the past and ahead into the future. During the interview, no limitations were placed on the ages at which life events could have occurred, and both positively and negatively appraised events were eligible to be described. We selected only four of the eight categories for the sake of brevity. The future chapter component corresponds to the domain assessed in the DIDS (future plans). The life theme section was chosen because it provides the central story line.

\section{Qualitative Analyses}

The six participants' life narratives were treated as single case studies (Woodside, 2010). The interview transcripts were analyzed using deductive thematic analysis (Braun \& Clarke, 2006), where the first two authors coded for identity dimensions in each narrative text. In the first step of analysis, each of the first two authors read the whole interviews of the six selected cases. Next, the two lead authors separately coded excerpts that corresponded to life goals exploration or decision-making. Next, the coded excerpts were united under the themes corresponding to the description of the six identity dimensions in the dual-cycle model (Luyckx et al., 2006, 2008). The relevant interview excerpts were coded for the presence or absence of each of the six identity dimensions. The coded material was exchanged between the first two authors, reviewed, and checked. Disagreements between the authors were discussed until consensus was reached (Syed \& Nelson, 2015). The interviews are condensed considering the study aims and summaries with relevant excerpts are presented here.

\section{Results and Discussion}

Unlike identity status interviews, in which identity statuses are assigned to the participants based on their descriptions of identity dimensions on explicit questions about commitments and exploration(s), we used life stories of participants assigned to different profiles based on the cluster analytic results. A lifestory interview method does not imply asking questions about exploration or commitment specifically. Nevertheless, in most narratives, participants described identity dimensions in their own words. The six cases are presented in the subsections immediately below.

\section{Achievement}

The first important chapter of K's (23-year-old male) life story is associated with starting multiple activities parallel to school: "it is one thing to be active at school and fulfill yourself, but it is a different thing when you reach out of this closed circle and begin looking for yourself in another environment by comparing and competing with your peers in different circumstances." In this first chapter, we can find proactive exploration in breadth, which continues in the next chapter about spending one semester abroad. The studying abroad experience served as a trigger for $\mathrm{K}$ to explore in breadth. He described as turning points those experiences when he was involved in forming and reconsidering his own beliefs, which we may qualify as a mixture of exploration in breadth, commitment-making, reflective 
exploration in depth, and reconsideration of commitments: "it was not something in particular, but it probably started from my going abroad for studies. On the one hand, it was the courses I took there, which taught me to ask questions; on the other hand, it was the relationship with my girlfriend... when we met, we would discuss many things, so these discussions and talks are very important to me; when you talk and discuss, you manage to understand yourself better.... This process is taking place now too." This excerpt suggests that exploration in breadth and commitment-making had continued over time. While making decisions about values or beliefs, K prioritizes critical reflection that points to reflective exploration in depth: "the most important thing is not just being committed to something, but asking yourself why you are committed... only in this case does one have the right to be committed to something."

The achievement story illustrates that commitment-making is preceded by exploration of different views, beliefs, and cultural contexts. The story involves reflection and critical thinking as necessary processes for decision-making. Here, we see how the life-story method provides information that could not be obtained from a quantitative survey: Specifically, we gain an understanding of the experiences that led to a person's present identity profile. Regarding the future, $\mathrm{K}$ mentions the following: "I always plan my future, but on the other hand, it is impossible to make any decent plans due to our environment." As $\mathrm{K}$ lives in a socioeconomic context of rapid change (Georgia), with an unstable labor market and a shortage of jobs, a sense of uncertainty regarding future decisions is a natural component of identity formation. In this passage, we observe the contextualized nature of life stories, which may not be evident in a quantitative survey. Instability and scarcity of jobs influences one's agentic aspirations even for the most proactive identity profile. Thus, the achievement story evidences commitment, while also expressing readiness for further exploration, which would be expected for an achieved profile. In the life theme component part of his life-story interview, $\mathrm{K}$ mentions: " ... freedom in thinking, the most important message is that a person should be free in thinking." This quote suggests that he is proactive and agentic.

\section{Foreclosure}

M's (22-year-old female) first chapter is her childhood that lasted to the age of 12 or 13 . She describes this period as ideal, when she had a lot of friends and her parents did everything for her to be happy. The next chapter is about her teenage years with exploration in breadth followed by commitments of adulthood: "[In the teenage years] I was not content with myself, protested a lot, my tastes changed ... In adulthood, I changed my interests, I set more serious goals, such as education or career, and an experience of living abroad...." Her turning point experiences are connected with her mother, who has been guiding her life up today: “. ... it has always been associated with my mother, she has a big influence on my life. Already as a child I knew what I was to do, for what I was born. My mother used to tell me that I was born to be a leader and there was never a moment when I made any decisions, everything was decided for me and I knew that this was going to happen, but I always did something to achieve this goal." This quote clearly indicates that, unlike the achieved respondent, $\mathrm{M}$ depended on her mother. At the same time, she made a decision to study abroad, to separate from her parents and be more independent, showing that there was some evidence of agency: “... By the time I entered adulthood, my interests have changed - the things that interested me were not interesting any more. I developed more serious goals such as study and career and living abroad ... I always wanted to see the world and not be attached to one place."

However, although the first part of the foreclosure story resembles exploration in breadth, the remainder of the excerpt makes clear that the respondent's life decisions were strongly influenced by her mother. In short, "everything was decided" for her. Identity status theory suggests that foreclosed people enact commitments without much exploration of different alternatives (Kroger \& Marcia, 2011; Marcia, 1966). Controlling parenting approaches, which impose parents' values and beliefs on children, may explain - at least in part - the developmental dynamics of the foreclosed status (Luyckx, Soenens, Vansteenkiste, Goossens, \& Berzonsky, 2007). Like many foreclosed people, $\mathrm{M}$ has quite a clear vision of her future: "I have plans at least for 10 years... I am going for a 2 year Master's, after that I will work in our partner company and after 5-6 years I want to work in a big company and I already know where it will be." $\mathrm{M}$ has made commitments and identifies herself with at least one such commitment in the career domain. Regarding her life theme, M mentions: "the most important for me is that I have a not monotonous, but diversified life. In my life there have always been interesting moments, and I hope there will be ...." This quote again points to outbursts of independence that reflects the path she has been following. She did explore to certain point and she plans to do so in the future. M's exploration in breadth and strong preference for nonmonotonous, diversified life do not reflect a typical foreclosure pattern, although her description of turning point decisions does appear to exemplify foreclosure.

\section{Searching Moratorium}

A (23-year-old female) plans to study abroad for 1.5 years. She divides her life into five chapters: childhood from birth to age 5 , adolescence from 5 to 13 , a self-exploration period from 13 to 18 , a self-assertion period from 18 to 22 , and goal attainment since age 22. She mentions that her development was associated with learning and reading literature, which formed her personality and her attitude toward her home country. She was thinking hard while making decisions about her future profession. A studied hard for university entry exams and enrolled with the best marks, but she was still not satisfied. "I was not satisfied with my studies at the university as I had totally different expectations. Perhaps, it was my fault as well that I did not manage to fit into the situation there, I am a bit disorganized, undecided and this... very much... at all stages of 
my life, of my conscious life, I have been wanting something... I always achieve whatever I do ... then I think it was nothing." Although she thinks she chose the correct profession, she still thinks being 17-18 years old is quite early for such serious decision-making. During her study years, A very much wanted to spend time in a foreign country, so, she took part in an exchange program and went to Latvia. This, according to her, was an important period in her life and helped her to look at her life differently. At the same time, she mentions “... but I have wanted this so much and once I achieved it, I had a feeling this is nothing at all.... so, I do not appreciate my own achievements ... there are more and more things I want to achieve. On the one hand, this is very good, because you never stop. One the other hand, it is a bit tiresome, because I am always unsatisfied...." In these passages, we can see that exploration in breadth is closely related with rumination, as attainment of goals rarely leads to satisfaction. During her university years, she participated in another exchange program, which was an important and interesting experience for her. After completing her degree, she began working for the university administration in a position she had wanted, but quite soon, she was not content and started another volunteer position. At present, she plans to go abroad to obtain her master's degree, which represents another long-time goal. In response to the question about her turning point experiences, she mentions, "Many events have had impacts on my life, very many factors from outside as well as from within. As I have already mentioned, this was a constant wish to achieve something and sense of not being satisfied. This has always been affecting me. I have always had such moments in my life, when I wanted something and could not reach it, but then I would achieve it anyway ...." A is quite certain about her future chapter: She plans to study during the next 2 years, and after that, marry, and start a job. In A's path toward commitments, we see that she is proactive, hardworking, and exploring many alternatives. At the same time, the driving force of exploration appears to be dissatisfaction with the current state of affairs. Searching moratorium is characterized by high scores on all identity dimensions including nonadaptive ruminative exploration and reconsideration of commitment (Beyers \& Luyckx, 2016). Based on A's case, we propose that constant dissatisfaction with attained goals might help to explain A's high reconsideration and rumination. In the central theme section, A summarizes her life story in the following way: "My whole life is finding myself and finding out what is going on, how things are going, what do we want, what do we need to do, what can we do. And, how we proceed after creating these frames... this is a never-ending process, until the end of life."

\section{Troubled Diffusion}

B (25-year-old male) outlined two chapters from his past: childhood and the formative period. "By the formative period I mean the time when you are preparing for something but are not involved in it fully." He describes his childhood as neither too positive nor too negative. He had an opportunity to develop and receive education. Regarding his university years, he regrets not having been diligent enough: "I studied to get a satisfactory grade. However, I knew I did not have the knowledge I wished to have.... This was all my carelessness...." B has a major in telecommunications but: "I have always been interested in literature and philosophy.... I studied engineering because it was a profession; however, I think I am more interested in theology and philosophy.... But, to say directly, one cannot earn a living by this profession." B describes as a turning point experience his encounter with death in his school years, which aroused his interest in topics associated with religion. When describing his future chapter, he mentions: "I can imagine my future in two ways - one which is colorful and one which is realistic. The colorful future is associated with pursuing a career in theology, doing research and teaching, and affording a decent standard of living in this way. This is how I imagine the colorful version, but I think there is no chance for it in Georgia .... The realistic one is to keep on with my current job and advance in it in terms of salary and skills." Exploration in breadth, intertwined with ruminative exploration, can be observed in this respondent's developmental path: $\mathrm{He}$ is in between two different life paths, one of which is associated with his true interests but is restricted by reality. Correspondingly, he describes the two potential future paths as "colorful" and "realistic." The perception of reality constraints on this participant's most desired aspiration (an academic career in theology) may have become a cause for rumination, pointing to importance of context while considering life stories. The case of troubled diffusion demonstrates how contextual restrictions on one's aspirations may be associated with ruminative exploration. Previous research (Skhirtladze et al., 2016) has indicated that exploration in breadth and ruminative exploration are closely related in the Georgian sample. This association may reflect socioeconomic difficulties in the Georgian context that do not permit young people to actualize the choices they have made. Combining life story and status approaches provides clearer illustration of the principle that identity formation is embedded in a social environment that guides and constrains one's decision-making. B's life theme illustrates the identity work he is involved in: "My idea of what I want? I ask this myself. This is a very bad question, because you do not know the final answer." This quote points to the typical diffusion pattern, where the person experiences difficulty answering important life questions, has trouble deciding where he belongs within society, and displays a great deal of rumination.

\section{Carefree Diffusion}

P (25-year-old male) divides his life story into three chapters: childhood, adolescence, and youth. His childhood memories are associated with social problems in his country, whereas his adolescence is marked by the start of exploration in breadth: "Adolescence was the time when my horizons started to expand. There were debates about what was right and what was wrong .... But when I think now, I would not change anything because it gives me experience for the future." $\mathrm{P}$ chose his 
profession without much thinking: "I decided to study in the field where I did not see myself... I do not know ... this is because of my stubborn nature...I am not a purposeful person... I am purposeful in not being purposeful...." So, he did not like the direction he had chosen and started to reconsider it: "I understood it was wrong to take the risk and choose the direction which was not mine. But I think I did everything I could. Nevertheless, I did not want to continue." After earning a bachelor's degree, $P$ decided to go to the war, which according to him, yielded interesting and valuable experiences. During that year, he discovered his talent for teaching and started to give private geography lessons to schoolchildren in geography. He reports leaving his parents' home as his turning point experience. These chapters point to identity processes and self-discovery, but it is not clear how proactive $\mathrm{P}$ was in these processes, so it is not possible to qualify them as exploration in breadth. His friend initiated and pushed him into the decision to continue his education: "my friend told me it was enough for us to sit at home and we'd better think of doing a master's. So, I took the entrance exams and thanks to my friend's persuasion, I am studying business management." P's life story does not show exploration prior to commitment-making. The decisions are either made out of the respondent's "stubborn nature" and his not being "purposeful" or are prompted by significant others (a friend's prompt to pursue a master's degree). The carefree diffusion case suggests that strong social relations and pressures might "force" people to make and implement choices even if they are not especially invested in the task of developing a sense of identity. Indeed, previous empirical findings from the Georgian cultural context, where social ties tend to be strong, indicate that proclivity toward avoidance and procrastination is closely related to a tendency to adhere to social rules and norms (Skhirtladze, Javakhishvili, Schwartz, \& Luyckx, 2017). Such a pattern would be atypical in a Western context, where individuals who are "drifting" would be less likely to follow rules and expectations (Berzonsky, 2011). Indeed, Western cultural contexts are generally "loose" and do not impose many rules and expectations on how young people should negotiate the transition to adulthood (Côté, 2014; Gelfand et al., 2011; S. J. Schwartz, 2016). P's comment on his future also suggests situational and passive approach to life goals and decisions: "I do not think about the future at all. I do not think about family or social position. These themes do not bother me. I think am not old enough for that and I am not psychologically ready ... I had a job but left it because I could not stay in a closed space for a long time.... I am more focused on episodic moments for gaining some experience...." His next plan is to take a year off from his studies in order to think about his future. P outlines freedom as the central theme of his life story: "I would say freedom-free behavior. ... I mean that I cannot create some image, in general I do not like when people create something artificially." He feels that he lacks clarity regarding his life decisions and tries to justify this by bringing forth a value of freedom as a guiding principle of his life.
Table 2. Features of Life Story Data for Six Identity Profiles.

Features That Life Story Data Exemplify, Show, Identity Profile or Clarify

\begin{tabular}{|c|c|}
\hline Achievement & $\begin{array}{l}\text { A1. Shows importance of critical thinking and } \\
\text { reflection for achieved profile } \\
\text { A2. Reveals the importance of exchange program } \\
\text { experiences for identity exploration } \\
\text { A3. Exemplifies the role of socioeconomic difficulties } \\
\text { leading to uncertainty regarding commitments }\end{array}$ \\
\hline oreclosure & $\begin{array}{l}\text { FI. Exemplifies externally directed decision-making } \\
\text { pattern, specifically parental authoritarian impact } \\
\text { F2. Shows the certainty and concreteness of the } \\
\text { future plans }\end{array}$ \\
\hline $\begin{array}{l}\text { earching } \\
\text { moratorium }\end{array}$ & $\begin{array}{l}\text { SMI. Clarifies dual nature of exploration-on the one } \\
\text { hand, permanent discontent with achievements } \\
\text { (rumination) and on the other hand, proactive } \\
\text { attitude leading to extending one's horizons and } \\
\text { self-development (exploration on breadth) }\end{array}$ \\
\hline $\begin{array}{l}\text { Troubled } \\
\text { diffusion }\end{array}$ & $\begin{array}{l}\text { TDI. Shows influence of socioeconomic restrictions } \\
\text { on identity formation processes leading to } \\
\text { rumination and indecisiveness }\end{array}$ \\
\hline $\begin{array}{l}\text { Carefree } \\
\text { diffusion }\end{array}$ & $\begin{array}{l}\text { CDI. Exemplifies diffusive and situational nature of } \\
\text { identity decision-making } \\
\text { CD2. Shows the pattern of contextual influence on } \\
\text { carefree diffusion's avoidant stance toward } \\
\text { commitments in more collectivistic cultural } \\
\text { contexts }\end{array}$ \\
\hline
\end{tabular}

\section{Undifferentiated}

V (22-year-old female) has four chapters in her life story: childhood, preparation for university entrance exams, student years, and looking for a job. She mentions that childhood was a truly carefree time, after which she started to prepare for university entrance exams: "Before this time I had not thought about anything seriously ... after that I started to prepare and studied for years at the university.... During the last year, I started to think about how to find a job. I had not thought about that before. I had no idea it might be so difficult." She wished to start as a teacher at school, but her attempt was not successful. This chapter indicates that $\mathrm{V}$ was not involved in identity work extensively - her description is quite short and suggests that, in her case, commitment was not associated with exploration. At the same time, in line with her DIDS scores, she enacted commitments. At present, she continues to look for a job. Her turning point experience is associated with the period when she became a student: "I was not independent before that... this [independence] continues after I graduated from the university.... I realized that everything depends on me. It was hard to understand .... I understood that I have to work, I have to help my parents and when I could not find a job I felt guilty." She talked briefly about her future chapter: "I think my future chapter will include the completion of my master's, finding a job, and having a family." The life story of this undifferentiated participant includes little information about exploration dimensions, although there is some evidence of commitment-making and identification with commitments. The life theme points 
to striving for success: "I think ... achievement of success, I always strive to success." This primary desire indicates that $\mathrm{V}$ has set quite an ambitious goal she has not manage to achieve yet, which, in turn, causes rumination.

The case summaries described here indicate that life-story material adds important information to the quantitative analysis by exemplifying and clarifying different aspects of profiles and dimensions. Table 2 summarizes these features.

It should be noted that not all the stories showed the typical combination of the profile-specific dimensions. For example, the foreclosure story included a description of exploration in breadth, which does not appear to be ideally illustrative of this profile. The identity dimensions and profiles are theoretical constructions, and their descriptions represent "ideal" representations of the concepts. In real cases, the dimensions and profiles might be manifested in different ways, and some discrepancies are expected.

\section{Conclusions}

A number of authors in the identity literature have outlined the importance of integrating across different approaches to examine personal identity (McLean \& Pasupathi, 2012; McLean \& Pratt, 2006; McLean, Syed, Yoder, \& Greenhoot, 2014; Vignoles et al., 2011). In the present article, we combined a quantitative, process-oriented approach (using the DIDS) with a qualitative, narrative approach (using the lifestory interview). As suggested by Syed and McLean (2016), our results indicate that these two approaches complement each other and, taken together, provide a more complete picture of identity development. Specifically, the life stories provide insight into ways in which the larger economic context constrains and frustrates young people's identity choices and in which family members and friends provide guidance that directs young people's choices.

We should highlight that the dual-cycle model served as the starting point for our analysis and that the life-story material was used to exemplify the dual-cycle categories. Indeed, our results indicated that life stories help to illustrate dimensions of identity formation and explain the differences across identity status profiles in terms of the ways young people address identity-related issues. The achievement story highlights the importance of critical thinking and reflection, the foreclosure story points to externally directed decision-making, the searching moratorium story exemplifies proactive exploration intertwined with less adaptive rumination caused by permanent discontent with oneself, the troubled diffusion story exemplifies how rumination might operate and highlights external factors that hinder commitment-making, the carefree diffusion story exemplifies situational decision-making and avoidance of commitment, and the undifferentiated story suggests little exploration in breadth and a paucity of identity work. Using quantitative measures, we obtain information regarding how individuals score on the six identity dimensions. Life narratives provide insight into how these identity processes might operate in the context of real-life situations.
Aside from its usefulness for exemplification, the life-story approach represents a way to contextualize identity formation. Although research has been conducted on contextual influences on identity formation within the quantitative tradition (e.g., Beyers \& Çok, 2008), our cases demonstrate that life stories are also valuable in illustrating the effects of context on identity dimensions. Through quantitative measures, we learn about identity dimensions and individual profiles created through combining these dimensions. Life stories provide information regarding how different contextual influences (e.g., controlling parenting approaches, lack of career opportunities, and close social ties) interact with identity dimensions and profiles. The achievement and searching moratorium stories illustrate ways in which study abroad experiences support exploration in breadth and how socioeconomic instability might lead to certain uncertainty regarding one's commitment. The foreclosure story illustrates connections between (a) controlling parenting approaches and (b) commitment-making without proactive exploration. The troubled diffusion story describes how lack of career opportunities might influence identity processes leading to rumination. The carefree diffusion story suggests ways in which decision-making might take place within the context of close social ties. The present research indicates that contextualizing identity dimensions within the larger sociocultural context represent a key advantage of integrating life story and dual-cycle model approaches. It is especially noteworthy that the life stories exemplified the ways in which the Georgian social, cultural, and economic context may have influenced the converge between and among identity dimensions - such as the close association between exploration in breadth and ruminative exploration.

The present results should be interpreted in light of at least three important limitations. First, the sample was small. We used one case to exemplify each identity profile. Given the heterogeneity in identity dimensions and life stories, it might be beneficial for future work to examine multiple cases for each profile. Second, our study was cross-sectional. Examining narratives over time might help to illustrate developmental changes in both identity dimensions and narrative life stories. Third, the results, especially their embeddedness within a specific sociopolitical context, might be specific to the Georgian social environment. As such, more research in other countries is needed.

Despite these limitations, our results suggest that integrating different methodologies for studying personal identity formation may expand our understanding of the identity development process. Adding qualitative material to quantitative results, and vice versa, would provide critical information regarding that might lead to new insights and study hypothesis for future research.

\section{Authors' Contribution}

Nino Skhirtladze contributed to conception, design, and acquisition; drafted the manuscript; critically revised the manuscript; gave final approval; and agreed to be accountable for all aspects of work ensuring integrity and accuracy. Nino Javakhishvili contributed to 
conception and acquisition; critically revised the manuscript; gave final approval; and agreed to be accountable for all aspects of work ensuring integrity and accuracy. Seth J. Schwartz contributed to conception and interpretation; critically revised the manuscript; gave final approval; and agreed to be accountable for all aspects of work ensuring integrity and accuracy. Koen Luyckx contributed to conception and interpretation; critically revised the manuscript; gave final approval; and agreed to be accountable for all aspects of work ensuring integrity and accuracy.

\section{Declaration of Conflicting Interests}

The authors declared no potential conflicts of interest with respect to the research, authorship, and/or publication of this article.

\section{Funding}

The authors received no financial support for the research, authorship, and/or publication of this article.

\section{References}

Adler, J. M., Dunlop, W. L., Fivus, R., Lilgendahl, J. P., Lodi-Smith, J., McAdams, D. P, ... Syed, M. (2017). Research methods for studying narrative identity: A primer. Social Psychological and Personality Science, 8, 519-527.

Arnett, J. J. (2008). The neglected 95\%: Why American psychology needs to become less American. American Psychologist, 63, 602-614. doi:10.1037/0003-066X.63.7.602

Baumeister, R. F., \& Muraven, M. (1996). Identity as adaptation to social, cultural, and historical context. Journal of Adolescence, 19, 405-416. doi:10.1006/jado.1996.0039

Berzonsky, M. D. (2011). A social-cognitive perspective on identity construction. In S. J. Schwartz, K. Luyckx, \& V. Vignoles (Eds.), Handbook of identity theory and research: Structures and processes (Vol. 1, pp. 55-76). London, England: Springer. doi:10.1007/9781-4419-7988-9_3

Beyers, W., \& Çok, F. (2008). Adolescent self and identity development in context. Journal of Adolescence, 31, 147-150. doi:10. 1016/j.adolescence.2008.03.002

Beyers, W., \& Luyckx, K. (2016). Ruminative exploration and reconsideration of commitment as risk factors for suboptimal identity development in adolescence and emerging adulthood. Journal of Adolescence, 47, 169-178. doi:10.1016/j.adolescence.2015.10.018

Braun, V., \& Clarke, V. (2006). Using thematic analysis in psychology. Qualitative Research in Psychology, 3, 71-101. doi:10. 1191/1478088706qp063oa

Carlsson, J., Wängqvist, M., \& Frisén, A. (2016). Life on hold: Staying in identity diffusion in the late twenties. Journal of Adolescence, 47, 220-229. doi:/10.1016/j.adolescence.2015.10.023

Côté, J. E. (2014). Identity-formation research from a critical perspective: Is a social science developing? In K. C. McLean \& M. Syed (Eds.), The Oxford handbook of identity development (pp. 527-538). Oxford, England: Oxford University Press. doi:10. 1093/oxfordhb/9780199936564.013.015

Cox, K., \& McAdams, D. P. (2010). The transforming self: Service narratives and identity change in emerging adulthood. Journal of Adolescent Research, 27, 18-43.

Crocetti, E., Luyckx, K., Scrignaro, M, \& Sica, S. L. (2011). Identity formation in Italian emerging adults: A cluster-analytic approach and associations with psychosocial functioning. European Journal of Developmental Psychology, 8, 558-572.

Crocetti, E., Rubini, M., \& Meeus, W. (2008). Capturing the dynamics of identity formation in various ethnic groups: Development and validation of a three-dimensional model. Journal of Adolescence, 31, 207-222. doi:10.1016/j.adolescence.2007.09.002

Erikson, E. H. (1968). Identity: Youth and crisis. New York, NY: Norton.

Gelfand, M., Raver, J., Nishii, L., Leslie, L., Lun, J., Lim, B. C., ... Yamaguchi, S. (2011). Differences between tight and loose societies: A 33-nation study. Science, 33, 1100-1104. doi:10.1126/science. 1197754

Habermas, T., \& Bluck, S. (2000). Getting a life: The emergence of the life story in adolescence. Psychological Bulletin, 126, 748-769. doi:10.10370T033-2909.126.5.741

House, R., Hanges, P., Javidan, M., Dorfman, P., \& Gupta, V. (2004). Culture, leadership, and organizations: The GLOBE Study of 62 Societies. Thousand Oaks, CA: Sage.

Kroger, J., \& Marcia, J. (2011). The identity statuses: Origins, meanings, and interpretations. In S. J. Schwartz, K. Luyckx, \& V. L. Vignoles (Eds.), Handbook of identity theory and research ( $p p$. 31-53). New York, NY: Springer.

Luyckx, K., Goossens, L., Soenens, B., \& Beyers, W. (2006). Unpacking commitment and exploration: Validation of an integrative model of adolescent identity formation. Journal of Adolescence, 29, 361-378.

Luyckx, K., Klimstra, T. A., Duriez, B., Van Petegem, S., Beyers, W., Teppers, E., \& Goossens, L. (2013). Personal identity processes and self-esteem: Temporal sequences in high school and college students. Journal of Research in Personality, 47, 159-170. doi:10.1016/j.jrp.2012.10.005

Luyckx, K., Schwartz, S. J., Berzonsky, M., Soenens, B., Vansteenkiste, M., Smits, I., \& Goossens, L. (2008). Capturing ruminative exploration: Extending the four-dimensional model of identity formation in late adolescence. Journal of Research in Personality, 42, 58-82. doi:10.1016/j.jrp.2007.04.004

Luyckx, K., Schwartz, S. J., Goossens, L., Beyers, W., \& Missotten, L. (2011). Processes of personal identity formation and evaluation. In S. J. Schwartz, K. Luyckx, \& V. L. Vignoles (Eds.), Handbook of identity theory and research (pp. 77-98). New York, NY: Springer. doi:10.1007/978-1-4419-7988-9_4

Luyckx, K., Soenens, B., Goossens, L., Beckx, K., \& Wouters, S. (2008). Identity exploration and commitment in late adolescence: Correlates of perfectionism and mediating mechanisms on the pathway to well-being. Journal of Clinical and Personality Psychology, 27, 336-361.

Luyckx, K., Soenens, B., Vansteenkiste, M., Goossens, L., \& Berzonsky, M. D. (2007). Parental psychological control and dimensions of identity formation in emerging adulthood. Journal of Family Psychology, 21, 546-550.

Mannerström, R., Hautamäki, A., \& Leikas, S. (2016). Identity status among young adults: Validation of the Dimensions of Identity Development Scale (DIDS) in a Finnish sample. Nordic Psychology, 69, 195-213. doi:10.1080/19012276.2016.1245156

Marcia, J. (1966). Development and validation of ego identity status. Journal of Personality and Social Psychology, 3, 551-558. doi:10. 1037/h0023281 
Mastrotheodoros, S., \& Motti-Stefanidi, F. (2016). Dimensions of Identity Development Scale (DIDS): A test of longitudinal measurement invariance in Greek adolescents. European Journal of Developmental Psychology, 14, 605-617. doi:10.1080/17405629. 2016.1241175

McAdams, D. P. (2001). The psychology of life stories. Review of General Psychology, 5, 100-122. doi:10.1037/1089-2680.5.2.100

McAdams, D. P. (2008). Personal narratives and life story. In O. P. John, R. W. Robins, \& L. A. Pervin (Eds.), Handbook of personality, theory and research (pp. 242-262). New York, NY: Guilford.

McAdams, D, (2011). Narrative identity. In S. J. Schwartz, K. Luyckx, \& V. L. Vignoles (Eds.), Handbook of identity theory and research (pp. 99-112). New York, NY: Springer.

McAdams, D. P., Bauer, J. J., Sakaeda, A.R., Anyidoho, N. A., Machado, M. A., Magrino-Failla, K., White, K. W., \& Pals, J. L. (2006). Continuity and change in the life story: A longitudinal study of autobiographical memories in emerging adulthood. Journal of Personality, 74, 1371-1400.

McAdams, D., \& McLean, K. C. (2013). Narrative identity. Current Directions in Psychological Science, 22, 233-238. doi:10.1177/ 0963721413475622

McAdams, D., \& Zapata-Gietl, C. (2015). Three strands of identity development across the human life course: Reading Erik Erikson in full. In K. C. McLean \& M. Syed (Eds.), The Oxford handbook of identity development (pp. 81-96). Oxford, England: Oxford University Press.

McLean, K. C., \& Pasupathi, M. (2012). Processes of identity development: Where I am and how I got there. Identity: An International Journal of Theory and Research, 12, 8-28. doi:10.1016/j.jrp.2007. 08.003

McLean, K. C., \& Pratt, M. W. (2006). Life's little (and big) lessons: Identity status and meaning-making in the turning point narratives of emerging adults. Developmental Psychology, 42, 714-722. doi: 10.1037/0012-1649.42.4.714

McLean, K. C., Syed, M., \& Shucard, H. (2016). Bringing identity content to the fore: Links to identity development processes. Emerging Adulthood, 21, 1-9. doi:10.1177/2167696815626820

McLean, K. C., Syed, M., Yoder, A., \& Greenhoot, A. F. (2014). The role of domain content in understanding identity development. Journal of Research on Adolescence, 26, 60-75. doi:10.1111/jora.12169

Pesigan, I. J. A., Luyckx, K., \& Alampay, L. P. (2014). Brief report: Identity processes in Filipino late adolescents and young adults: Parental influences and mental health outcomes. Journal of Adolescence, 37, 599-604. doi:10.1016.j.adolescence.2014.04.012

Ritchie, R. A., Meca, A., Madrazo, V. L., Schwartz, S. J., Hardy, S. A., Zamboanga, B. L., ... Lee, R. M. (2013). Identity dimensions and related processes in emerging adulthood: Helpful or harmful? Journal of Clinical Psychology, 69, 415-432. doi:10.1002/jclp. 21960

Roberts, K., \& Pollock, G. (2009). New class divisions in the new market economies: Evidence from the careers of young adults in postSoviet Armenia, Azerbaijan and Georgia. Journal of Youth Studies, 12, 579-596.

Roberts, K., Pollock, G., Manasyan, H., \& Tholen, J. (2008). Schoolto-work transitions after two decades of post-communism: What's new?' Eurasian Journal of Business and Economics, 1, 103-129.
Robinson, O. C. (2014). Sampling in interview-based qualitative research: A theoretical and practical guide. Qualitative Research in Psychology, 11, 25-41. doi:10.1080/14780887.2013.801543

Robinson, O. C., \& McAdams, D. P. (2015). Four functional roles for case studies in emerging adulthood research. Emerging Adulthood, 3, 413-420. doi:10.1177/2167696815592727

Schwartz, S. H. (2006). Basic human values: Theory, measurement, and applications. Revue Française de Sociologie, 47, 249-288.

Schwartz, S. J. (2016). Turning point for a turning point: Advancing emerging adulthood theory and research. Emerging Adulthood, 4, 300-317. doi:10.1177/2167696815624640

Schwartz, S. J., Beyers, W., Luyckx, K., Soenens, B., Zamboanga, B. L., Forthun, L. F., .. W Waterman, A. S. (2011). Examining the light and dark sides of emerging adults' identity: A study of identity status differences in positive and negative psychosocial functioning. Journal of Youth and Adolescence, 40, 839-859. doi:10.1007/ s10964-010-9606-6

Schwartz, J. S., Luyckx, K., \& Crocetti, E. (2015). What have we learned since Schwartz (2001)? A reappraisal of the field of identity development. In K. C. McLean \& M. Syed (Eds.), The Oxford handbook of identity development (pp. 539-561). Oxford, England: Oxford University Press.

Schwartz, S.J., Zamboanga, B. L., Meca, A., \& Ritchie, R. A. (2012). Identity around the world: An overview. New Directions for Child and Adolescent Development, 138, 1-18.

Skhirtladze, N., Javakhishvili, N., Schwartz, J. S., Beyers, W., \& Luyckx, K. (2016). Identity processes and statuses in postSoviet Georgia: Exploration processes operate differently. Journal of Adolescence, 47, 197-209. doi:10.1016/j.adolescence. 2015.08.006

Skhirtladze, N., Javakhishvili, N., Schwartz, J. S., \& Luyckx, K. (2017). Identity styles in Georgian context and their association to parenting dimensions. European Journal of Developmental Psychology, 1-17. doi:10.1080/17405629.2017.1334549

Syed, M. (2010). Developing an integrated self: Academic and ethnic identities among ethnically diverse college students. Developmental Psychology, 46, 1590-1604. doi:10.1037/a0020738

Syed, M., \& McLean, K. C. (2016). Understanding identity integration: Theoretical, methodological, and applied issues. Journal of Adolescence, 47, 109-118. doi:10.1016/j.adolescence.2015.09.005

Syed, M., \& Nelson, S. (2015). Guidelines for establishing reliability when coding narrative data. Emerging Adulthood, 3, 375-387. doi: $10.1177 / 2167696815587648$

Vignoles, V., Schwartz, S. J., \& Luyckx, K. (2011). Introduction: Towards and integrative view of Identity. In S. J. Schwartz, K. Luyckx, \& V. Vignoles (Eds.), Handbook of identity theory and research: Structures and processes (Vol. 1, pp.55-76). London, England: Springer.

Woodside, A. G. (2010). Case study research: Theory, methods, practice. Wagon Lane, Bingley, England: Emerald Group Publishing Limited.

Zimmermann, G., Lannegrand-Willems, L., Safont-Mottay, C., \& Cannard, C. (2013). Testing new identity models and processes in French-speaking adolescents and emerging adults students. Journal of Youth and Adolescence, 8, 1-15. doi:10.1007/s10964013-0005-7 


\section{Author Biographies}

Nino Skhirtladze, $\mathrm{PhD}$ is an assistant professor at the Ilia State University and researcher at the D. Uznadze Institute of Psychology, Georgia. Her research focuses on the identity development, parenting and the transition to adulthood.

Nino Javakhishvili is a director of the D. Uznadze Psychology Institute and psychology professor at the school of Arts and Sciences of Ilia State University, Tbilisi, Georgia. Her research interest is in social and personality psychology, study of identity and prejudice among them.
Seth J. Schwartz is Professor of Public Health Sciences at the University of Miami Leonard M. Miller School of Medicine. He has a master's degree in family and child sciences from Florida State University and a $\mathrm{PhD}$ in developmental psychology from Florida International University. His research interests include identity, acculturation, and well-being and problem outcomes during adolescence and the transition to adulthood.

Koen Luyckx is an associate research professor at University of Leuven where he received his $\mathrm{PhD}$ in 2006. His current research interests include identity development, psychopathology, and chronic illness. 